\title{
Modelling the System of Diversified Inventory Management
}

\section{Babenko Inna Viktorovna}

Southwest State University

babenkoinny@gmail.com

\section{Tsyklauri Viktoriya Yurievna}

Southwest State University vika-ts@mail.ru

\section{Doi:10.5901/mjss.2015.v6n6s4p489}

\begin{abstract}
The relevance of studying the models of diversified inventory management is caused, firstly, by the complexity and diversity of management process, and, secondly, by a large proportion of logistical costs in overall enterprise costs. The primary value of inventory management models is to increase the qualitative level of meeting various kinds of needs by material resources and improving the reliability of economic system performance. The article considers the process of modelling the system of diversified inventory management. A Special attention is paid to the mathematical forecasting model of implementing, determining the reorder level and order quantity. A feature of the present model is that it involves only the logic of the process, since the variety of control algorithms modifications may cause certain difficulties of creating a universal model. In the given model, a controllable parameter is the time required to dispose of the remainder of stock, which enables us to take into account, firstly, the forecast demand for resources, and, secondly, the restrictions on the production capacity.
\end{abstract}

Keywords: Manufacturing inventory, Diversified inventory, Model of inventory management, Algorithm for inventory management, Model of optimal periodic control

\section{Introduction}

Manufacturing inventory typically includes a wide range of materials. It is generally accepted that the accuracy of norm setting must match the importance of the material. It is important to determine what kind of inventory system one has since it will affect which formulas to use for different calculations. When optimizing inventory it is a common opinion that the optimum solution can be determined, but this is not always the case. If the system is of a complex nature more approximations has to be used, since the connection between different warehouses has to be considered. Efficient inventory control includes how the inventory are scheduled properly, no delays between sniffing of raw materials and goods. The amount of raw materials determines the workforce and other factors. The different echelon systems can be divided into two different models, a single echelon system and a multi echelon system. A fundamental issue in the theory and practice of inventory management has been the modeling of random demand since the inception of stochastic inventory models in the 1950s. The questions of the theory of inventory management were considered by the following authors: Anikin B. A., Belyaev Yu.A., Goldobina H.H., Golenko D. I., Inyutina K.V. Thus, authors developed the methods and models of inventory management intended for resources of organization. Much attention of scientists-economists and specialists of the enterprises dedicate to problems of improvement of management of material stocks and streams. However, at all undoubted importance of this problem its theoretical study isn't complete. Practical techniques operate with the integrated cost indexes that is too difficult for management organizations.

So, the development of models of rationing and operational management of inventory on the basis of complex model of dynamics of material and cash in a commercial cycle of the enterprises is topical.

The goal is to choose the technique of norm setting for each group of materials, which would correspond to the significance of this group. The purpose of calculating standard inventory is to determine some volumes of stocks. In this issue the authors of techniques do not differ from each other: inventory must ensure the minimization of aggregate costs on its formation, keeping and losses due to deficit. Moreover, this requirement in the case of deficit impermissibility transformed into the following provision: rate of stock should define minimum stock, in full (or with probability close to 1 ) ensuring production needs in the planned period. That is the main criterion for evaluating different techniques. And if this 
problem is solved, then a natural requirement is to minimize costs for finding the norm: these costs also should be included in inventory formation costs.

Supply system includes the stocks of different resources, the number of which can vary from a few to several thousand item names. In the general case, diversified inventory management system is large, complex and multi-layered. In this system, the movement of stored items due to their offtake, arrival and putting aside as a reserve is the material flow ensuring a normal operation process. If material flow is being ceased, so is the process of inventory management. Consequently, information flow consists of a set of messages about the movement of material flow (inventory) at different parts of operating cycle.

In general terms the purpose of a system's functioning can be formulated as the satisfaction of consumers' demand for stored and managed resources. The goal of functioning in this formulation can be achieved, if managed inventory lists are sufficient for production, i.e. not scarce, are in demand with consumers, will be constantly in stock and will be available to consumers. The subject of consumption is the most detailed specific lists of items. Therefore, day-today inventory management should be carried out against detailed lines items.

\section{Materials and Methods}

In the general case the purpose of diversified inventory management is providing the main path towards the goal of functioning. The general statement of purpose can be specified as the minimum aggregate costs per unit of outputs in relation to inventory management. Therefore, taking into account the goal of functioning the system of diversified inventory management can be considered as a conditionally elementary one. In the management process the stocks of resources serve as a managed object. Mass management operations are the reaction of a controlled object to regular perturbations of external environment. The controlled parameter should reflect the ability of a managed object as to achieving the goal of functioning regardless of quantitative values of the parameter of perturbated effects. Thus, we should choose a relative level of inventory rather than an absolute one as a controlled parameter. That parameter may be the time of disposing of stock remainder.

The system of diversified inventory regulation has the following features of management process:

- A considerable number of inventory items lists being stored and managed are subjected to control process;

- Demand is accidental, the information on its dissemination is not available, the general information is data about the current disposal of resources;

- Current keeping in supplies is carried out with significant lag in comparison with the period of decision making;

- The target level of satisfying consumers ' demand for inventory is assumed to be $100 \%$, i.e. the deficit is considered to be strictly unacceptable.

The function minimizing the aggregate costs associated with inventory with restrictions is taken as a target function - the amount of stock at any one time must be greater than zero.

The optimal order size on any managed lines item is considered to be independent of the order size on the other lines items.

The size and reorder level at a constant period of inventory checks are taken as variables in the model.

The model of optimal periodic control of diversified inventory is described by the following mathematical representation:

$$
\begin{aligned}
& \mathrm{X}_{\mathrm{i}, \mathrm{t}}^{*}=\left\{\begin{array}{l}
X_{i, t} * C+X_{t-1}^{*} *(1-C) ; Z_{i, t}>0 \\
X_{i, t-1} ; Z_{i, t}=0
\end{array}\right\} \\
& \left.t_{i, t}^{p o}=\frac{\left(Z_{i, t}+z_{i, t}\right)}{X_{i, t}^{*}}-R-t_{i}^{s t}+1\right) \\
& Z_{i, t}=Z_{i, t-1}-X_{i . t}+Y_{i, t} \text {; } \\
& z_{i, t}=z_{i, t-1}-Y_{i, t}+q_{i, t}^{* *} \text {; } \\
& q_{i, t}=\left\{\begin{array}{l}
q_{i, t}^{*} ; t_{i, t}^{p o} \leq L_{i} ; \\
0 ; t_{i, t}^{p o}>L ;
\end{array}\right.
\end{aligned}
$$


$q_{i, t}^{*}=\left\{\begin{array}{l}\sqrt{\frac{2 C^{3}}{C_{i}^{x p}}} * \sqrt{X_{i, t}^{*}} ; \frac{2 C^{3}}{C_{i}^{x p}} \geq \frac{X_{i, t}^{*}}{2} \\ X_{i, t}^{*}<0 ; \frac{2 C^{3}}{C_{i}^{x p}} \geq \frac{X_{i, t}^{*}}{2}\end{array}\right\}$

$$
\begin{aligned}
& Y_{i, t}=q_{i, t-L}^{*} ; \\
& t^{p o} \leq t_{\max } ; \\
& t_{\max }=f(R ; L) ; \\
& 0<C<1 \\
& t=1,2, \ldots, N ; \\
& \text { Where, }
\end{aligned}
$$

$X_{i}^{*}$ - the forecast value of inventory disposal of the stored and managed list of items $i$ in relation to the corresponding moment of decision making $(\mathrm{t}-1 ; \mathrm{t})$;

$\mathrm{X}_{i}-$ the actual disposal of list of items $i$ in relation to the corresponding moment of decision making;

$\mathrm{t}$ - the current moment of decision taking;

$\mathrm{C}$ - the weighting factor of the forecast model;

$\mathrm{Z}_{i}$ - the actual stock of list of items $i$;

$\mathrm{Zi}_{\mathrm{i}}$ - the amount of orderings to replenish the stock of list of items $i$;

$t_{i, t}^{p o}$ - the forecast time of disposing of the stock remainder of list of items $i$ at the time of decision making $t$.

$\mathrm{R}$ - the period of inventory check (the period between the adjacent points of decision making);

$t_{i}^{s t} \quad$ - security stock of the stored list of items with the days of forecast disposal;

$\mathrm{q}_{\mathrm{i}, \mathrm{t}} ; q_{i, t}^{*} ; q_{i, t}^{* *}$ - the order quantity to replenish inventory at the different stages of settling with accounts;

$\mathrm{L}-\quad \operatorname{lag}$ (the period of time between ordering for the next replenishment of stock and its entering the warehouse);

$\mathrm{C}^{3}$ - unit costs of order;

$\mathrm{C}^{\mathrm{xp}}$ - unit costs of holding.

Determining the optimum order point (1) means that if by the time of the next stock check it turns out that the disposal period of actual inventory remainder and the amount of previously made but not yet received orderings is no more than the value of lag, the next order is made while checking the present status of inventory, i.e. in the current moment of decision making.

The expression (2) is the determination of the optimum order point with minimal aggregate costs for separate stored and managed lists of items.

The magnitude of lag is determined proceeding from the specific conditions of specific lists of items supplies and the specific storage, and inventory management facilities.

The decision-making period should be chosen as a minimal one, since it provides a minimum of errors.

In order to ensure the comparability of experimental calculations' results for all options the value of the weighting coefficient was taken as $\mathrm{C}=0,5$, and the entry conditions were determined on the basis of the following expressions.

$$
\begin{aligned}
& \mathrm{X}_{0}^{*}=0,1 \sum_{t=1}^{10} X_{t} ; \\
& t_{z}^{p o}=L+1 ; \\
& Z_{0}=X_{0}^{*} t_{z}^{p o} ; \\
& z_{0}=q_{0} ; \\
& q_{0}=\sqrt{\frac{2 C^{3}}{C^{x p}}} * \sqrt{X_{0}^{*}} ;
\end{aligned}
$$


Where $t_{z}^{p o}$ - the disposal period of actual stock remainder at depot excluding the amount of previously made but not yet received orderings;

$Z_{0}$ - absolute amount of actual stock at the moment preceding the settlement of accounts excluding the quantity of previously made but not yet received orderings

\section{Results and Discussion}

For the model implementation there have been used 3 dynamic time series of disposal of stored list of items. In order to ensure the comparability of results for all three time series we keep the following parameters: series configuration, mean deviation and quadratic deviation. The time series differ only in the values of variation coefficients of mean and quadratic deviations that relate to the value of variation coefficients of the first time series as 1:1/4:1/16. In the same proportion there have been taken costs relationships of $C^{3 /} C^{x p}(2000 ; 500 ; 125)$. The values of lag were chosen as 20,10 and 5 days, i.e. in the ratio 1:1/2:1/4, due to the limits of variation of this parameter in practice.

Table 1: The results of experimental verification of a periodic regulation model performance of diversified inventory.

\begin{tabular}{|c|c|c|c|c|c|c|c|c|}
\hline № & $\bar{x}$ & $\begin{array}{l}\text { VI (linear deviation } \\
\text { coefficient) }\end{array}$ & $\begin{array}{c}\mathrm{V} \sigma \text { (quadratic deviation } \\
\text { coefficient) }\end{array}$ & V/V1 & $\begin{array}{l}\text { The ratio of } \\
\text { costs }\end{array}$ & $\begin{array}{c}\text { Lag, the number of } \\
\text { days. }\end{array}$ & L/L1 & $\bar{Z}$ \\
\hline \multirow[t]{9}{*}{$1-9$} & \multirow[t]{9}{*}{31,65} & \multirow[t]{9}{*}{39,2} & \multirow[t]{9}{*}{45,9} & \multirow[t]{9}{*}{1} & 2000 & 20 & 1 & 13,91 \\
\hline & & & & & 2000 & 10 & $1 / 2$ & 17,85 \\
\hline & & & & & 2000 & 5 & $1 / 4$ & 11,82 \\
\hline & & & & & 500 & 20 & 1 & 11,49 \\
\hline & & & & & 500 & 10 & $1 / 2$ & 14,67 \\
\hline & & & & & 500 & 5 & $1 / 4$ & 9,53 \\
\hline & & & & & 125 & 20 & 1 & 10,78 \\
\hline & & & & & 125 & 10 & $1 / 2$ & 12,13 \\
\hline & & & & & 125 & 5 & $1 / 4$ & 9,11 \\
\hline \multirow[t]{9}{*}{$10-18$} & \multirow[t]{9}{*}{131,65} & \multirow[t]{9}{*}{9,2} & \multirow[t]{9}{*}{11,3} & \multirow[t]{9}{*}{$1 / 4$} & 2000 & 20 & 1 & 8,87 \\
\hline & & & & & 2000 & 10 & $1 / 2$ & 4,58 \\
\hline & & & & & 2000 & 5 & $1 / 4$ & 3,69 \\
\hline & & & & & 500 & 20 & 1 & 7,81 \\
\hline & & & & & 500 & 10 & $1 / 2$ & 4,97 \\
\hline & & & & & 500 & 5 & $1 / 4$ & 2,45 \\
\hline & & & & & 125 & 20 & 1 & 7,58 \\
\hline & & & & & 125 & 10 & $1 / 2$ & 3,54 \\
\hline & & & & & 125 & 5 & $1 / 4$ & 1,79 \\
\hline \multirow[t]{9}{*}{$19-25$} & \multirow[t]{9}{*}{531,65} & \multirow[t]{9}{*}{3,2} & \multirow[t]{9}{*}{2,9} & \multirow[t]{9}{*}{$1 / 16$} & 2000 & 20 & 1 & 5,78 \\
\hline & & & & & 2000 & 10 & $1 / 2$ & 3,54 \\
\hline & & & & & 2000 & 5 & $1 / 4$ & 2,55 \\
\hline & & & & & 500 & 20 & 1 & 5,28 \\
\hline & & & & & 500 & 10 & $1 / 2$ & 2,34 \\
\hline & & & & & 500 & 5 & $1 / 4$ & 1,73 \\
\hline & & & & & 125 & 20 & 1 & 0,35 \\
\hline & & & & & 125 & 10 & $1 / 2$ & 0,21 \\
\hline & & & & & 125 & 5 & $1 / 4$ & 0,18 \\
\hline
\end{tabular}

The conducted verification of the model shows the possibility of its use at high performance indicators, such as meeting the demand for stocks of material resources with rather low levels of average daily stock in the days of disposal.

The algorithm of diversified inventory management is represented in Figure 1. 


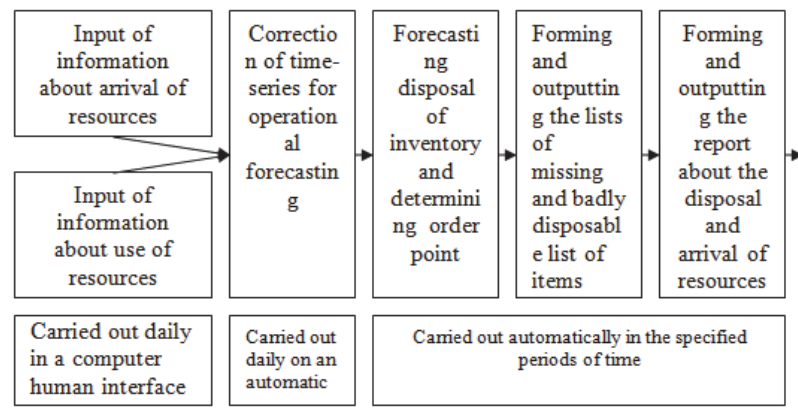

Figure 1: Management algorithm of automatic diversified inventory control system

The mathematical model of forecasting disposal and determining the order point is implemented according to the algorithm presented in Figure 2.

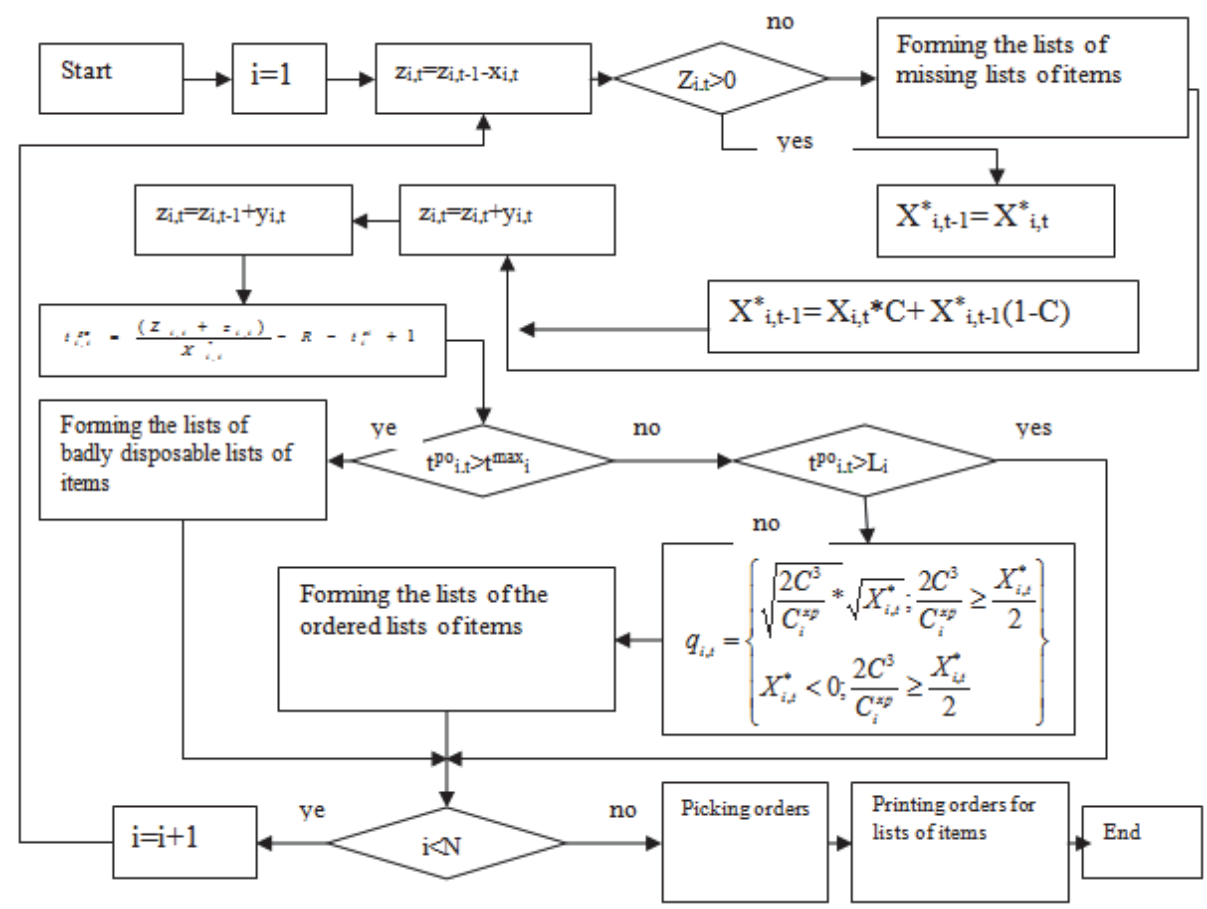

Figure 2: The algorithm of periodic forecasting of disposal, determining the order point and the optimal order quantity for replenishment

\section{Conclusion}

The versatility of the model of day-to-day diversified inventory management is caused by the fact that this model takes into account only the logic of the process. The peculiarity of operating information tasks lies in the variety of specific modifications of algorithms for their implementation, each of which is defined at every moment of decision taking. In practice it is almost impossible to develop a universal algorithm for such tasks. When studying information tasks related to diversified inventory management, you may find that the whole variety of management operations is formed from a 
limited number of sets of management activities, the structure of which, with all possible modifications of the system, remains unchanged.

\section{References}

P.Radhakrishnan, V.M.Prasad, M. R. Gopalan (2009) Inventory Optimization in Supply Chain Management using Genetic Algorithm. IJCSNS International Journal of Computer Science and Network Security, VOL.9 No.1

Lu, X., J. S. Song, A. C. Regan. (2006) Inventory planning with forecast updates: Approximate solutions and cost error bounds. Oper. Res. 54 1079-1097.

Retsef Levi, Robin O. Roundy, David B. Shmoys, Van Anh Truong. Approximation Algorithms for Capacitated Stochastic Inventory Control Models Operations Research 56(5), pp. 1184-1199

Maciej Kubon, Andrzej Krasnodębski (2010). Logistic costs in competitive stratebgies of enterprises. Agric. Econ. - Czech, 56, (8): 397402

Zoltán Bokor (2012) Cost calculation model for logistics service providers. Promet - Traffic\&Transportation, Vol. 24, No. 6, 515-524

Lukinskiy V.V. (2008) Actual problem of theory inventory. St Petersburg: SPbGIEU, pp. 212

Belousova L.S., Migunova E.A., Babich T.N. (2012) Theoretical aspects of explorer of economic potential as a object of the planning on enterprises. Proceeding of SWSU. № 4-3 (43), pp. 65-75

Bauersoks Donald Dzh. (2006) Logistics: the integrated chain of deliveries. / Bauersoks Donald Dzh. Kloss David, 640 p.p 